\title{
Erratum to: Mutual Effect of Steelmaking Slag Layer Depth and Diameter on Alkali Elution Rate in Open Channel Vessels with Straightened Seawater Flow
}

\author{
Go Takeuchi ${ }^{1} \cdot$ Hironori Tamaki $^{1} \cdot$ Md. Azhar Uddin $^{1} \cdot$ Yoshiei Kato $^{1} \cdot$ Eiji Kiso $^{2} \cdot$ Katsunori Takahashi $^{3}$
}

Published online: 16 December 2016

(C) The Minerals, Metals \& Materials Society (TMS) 2016

\section{Erratum to: J. Sustain. Metall.}

\section{DOI 10.1007/s40831-016-0107-z}

Readers should note that there was an error in Eq. (9) in this article as originally published Online First:

In the right side of the equation,

$\rho u / \mu$ was given instead of $\rho u d / \mu$

The online version of the original article can be found under doi:10.1007/s40831-016-0107-z.

Yoshiei Kato

y-kato@cc.okayama-u.ac.jp

Go Takeuchi

ev422419@s.okayama-u.ac.jp

Hironori Tamaki

ev418426@s.okayama-u.ac.jp

Md. Azhar Uddin

alazhar@cc.okayama-u.ac.jp

Eiji Kiso

kiso.664.eiji@jp.nssmc.com

Katsunori Takahashi

kats-takahashi@jfe-steel.co.jp

1 Department of Material and Energy Science, Graduate

School of Environmental and Life Science, Okayama

University, 1-1 Tsushima-naka, 3-chome, Kita-ku,

Okayama 700-8530, Japan

2 Marketing Development, Slag \& Cement Division, Nippon Steel \& Sumitomo Metal Corporation, Tokyo, Japan

3 Slag \& Refractories Research Department, Steel Research Laboratory, JFE Steel Corporation, Fukuyama, Japan 